\title{
Concept Mapping As A Learning Tool For The Employment Relations Degree
}

Ricardo Martínez-Cañas, Ph. D., University of Castilla-La Mancha, Spain

Pablo Ruíz-Palomino, Ph. D., University of Castilla-La Mancha, Spain

\begin{abstract}
Concept mapping is a technique to represent relationships between concepts that can help students to improve their meaningful learning. Using the cognitive theories proposed by Ausubel (1968), concept maps can help instructors and students to enhance their logical thinking and study skills by revealing connections among concepts that can simplify all the new concepts that can be introduced in a subject during any subject classes of a semester. In this paper a study is made for the introduction of this technique in the subject Business Management Principles as part of the Employment Relations Degree. The main objective of this paper is to analyze the impact of concept mapping on the learning acquired by the students. For this purpose we use data with the evolution of qualifications of students as the items that show how a planned way of introducing new concepts (relating with concepts that students already have) can be very useful in college teaching. Therefore this paper analyzes within a specific context the way in which concept maps are constructed to reflect student's knowledge and facilitate their sense-making and improve their meaningful learning.
\end{abstract}

Keywords: Concept Mapping; Teaching Innovation; Meaningful Learning

\section{INTRODUCTION}

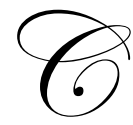

oncept mapping is considered as a learning technique that is mainly used for graphical representation of knowledge (Novak, 1998). This technique was formerly created and developed at Cornell University (Novak and Gowin, 1996) and is based on the theory of "Meaningful learning" proposed by Ausubel (1968). This theory supports the hypothesis that "the most important factor in learning is what the subject already know", and that is why learning can be planned from this premise. From this point of view instructors can plan intentionally and with an explicit character what new concepts should be introduced to students that could perfectly fit inside the subject aims and therefore complementing concepts that students already have at the beginning of the subject (Ausubel, 2002). What this technique is helping is a meaningful learning that occurs in a planned way, more exactly, when a student is able to depict a set of relationships between the concepts that previously have and the new concepts that is learning in a concrete subject classes. During the process of linking and connecting concepts is when there are a number of changes in the cognitive structure of the subjects by altering their perception and complementing the meaning they attach to the concepts already mastered (Novak and Gowin, 1996). In this way, when students improve their meaningful learning they are able to raise additional links between old and new concepts.

The use of this learning technique is not designed to replace any lesson plans, exercises, case studies, practices and other activities planned in the semester subjects, but it is just an ideal complement for former activities because it facilitate students to develop an active learning (Novak, 1998). Also is important to remark that if an instructor delete basic or key activities on the subject could limit the expected significant learning (Castillo-Olivares, 2001). The active process resulting in the maps requires the student or students must interact, to play with the concepts as it primarily to deepen into the content. It is not a simple memorization, as the student or student group should pay attention to the relationship between concepts (Novak, 1998). That is why this technique it is used as part of the ongoing assessment activities of students. 
Concept maps were initially developed as a powerful data analysis tool that in a more precisely way are graphical tools for organizing and representing knowledge. They include concepts, usually enclosed in circles or boxes of some type, and relationships between concepts indicated by a connecting line linking two concepts. Words on the line referred to as linking words or linking phrases, specify the relationship between the two concepts (Novak and Cañas, 2006).

In recent years concept mapping has become a powerful tool which is frequently applied in different contexts and levels (from primary schools to Universities) in science education. Teachers ask their students to describe their knowledge by means of specific terms and explain connections between them. Researchers ask students to construct concept maps to gain information about students' conceptions of various topics in science (Iuli and Helldén 2004). Concept mapping stimulates learners to articulate and externalize and depict graphically the actual state of their knowledge.

Since Novak and Gowin (1996) noted that concept mapping is a creative activity, in which the learner must exert effort to clarify concept meanings in a specific domain knowledge, by identifying important concepts, establishing the concepts relationships, and denoting their structure (Gouli et al. 2004). Concept mapping can be an excellent activity in assessing students' prior knowledge, which is of great importance since prior knowledge is a determining factor in subsequent learning (Gouveia and Valdares 2004). In this work concept mapping is applied to evaluate the knowledge acquired on the subject Business Management Principles in the degree of Employment Relationships in Castilla-La Mancha University. The study analyzed 15 groups of students, allowing us, on the one hand, to evaluate the students initial knowledge on Business Management and identify their misunderstandings and gaps - very useful information to improve the courses - and on the other hand, to evaluate the changes produced by the courses in the students understanding of Management principles.

\section{CONCEPT MAPS}

The meaning of concepts can be are acquired either by discovery, which is the way children acquire their first concepts and language, or by open learning, which is how children learn at school and adults at University (Novak, 1998). Thus, learning from this perspective, occurs when a person is able to make a diagram that shows relationships between concepts contained new and previously acquired concepts. This implies a series of changes in cognitive structure, changing the perception of existing concepts and forming new links between them. This is because the learning lasts longer and is better than simply memorizing because the new concepts take longer time to forget, and can be more easily applied in problem solving activities (Novak and Gowin, 1996).

The objective of using maps is twofold: on one hand the teacher lets you go building with students and explore their prior knowledge available, and secondly organize, interrelate and establish the knowledge of the content studied for students. The concept mapping also promotes reflection, analysis and creativity. Therefore, "the concept map appears as a tool of partnership, relationship, discrimination, description and exemplification of content, with a high power of visualization" (Castillo-Olivares, 2001, p.45).

Concept maps are widely used in education and business (Moon et al., 2011). And their main uses for academic purposes include:

- $\quad$ Note taking and summarizing gleaning key concepts, their relationships and hierarchy from documents and source materials

- $\quad$ New knowledge creation: e.g., transforming tacit knowledge into an organizational resource, mapping team knowledge

- Institutional knowledge preservation (retention), e.g., eliciting and mapping expert knowledge of employees prior to retirement

- $\quad$ Collaborative knowledge modeling and the transfer of expert knowledge

- $\quad$ Facilitating the creation of shared vision and shared understanding within a team or organization

- Instructional design: concept maps used as "advance organizers" which provide an initial conceptual frame for subsequent information and learning. 
- $\quad$ Training: concept maps as "advanced organizers" to represent the training context and its relationship to their jobs, to the organization's strategic objectives, to training goals.

- $\quad$ Increasing meaningful learning

- $\quad$ Communicating complex ideas and arguments

- $\quad$ Examining the symmetry of complex ideas and arguments and associated terminology

- Detailing the entire structure of an idea, train of thought, or line of argument (with the specific goal of exposing faults, errors, or gaps in one's own reasoning) for the scrutiny of others.

- $\quad$ Enhancing meta-cognition (learning to learn, and thinking about knowledge)

- $\quad$ Improving language ability

- $\quad$ Knowledge elicitation

- Assessing learner understanding of learning objectives, concepts, and the relationship among those concepts

- $\quad$ Lexicon development

Therefore, concept maps are used to stimulate the generation of ideas, and are believed to aid creativity and brain-storming. Although they are often personalized and idiosyncratic, concept maps can be used to communicate complex ideas. Formalized concept maps are used in specific subjects as software design, where a common usage is Unified Modeling Language diagramming amongst similar conventions and development methodologies. Concept mapping can also be seen as a first step in ontology-building, and can also be used flexibly to represent formal argument (Novak and Cañas, 2006). So, and due that this technique help students to develop a significant learning during classes of a semester we can propose as our main working hypothesis that:

"Students that make continuous activities throughout the course obtain a better learning and therefore have better final qualifications in their concept maps activities at the end of the course".

\section{METHODS AND RESULTS}

To test our hypothesis, we conducted an empirical study described below. The study had a population of 51 students from the course Business Management Principles for the first year and second semester of the degree in Employment Relations at the Faculty of Social Sciences of Castilla-La Mancha in the city of Cuenca (Spain).

The sample was joined in 15 groups of 2 to 4 students. Although the ideal work would have been to make one concept map in every lecture, the high number of students, units, together with the limited time available make us to think in reorganize students in groups to build two concept maps as class work activities. These students built in two sessions of 60 minutes, two conceptual maps in two different periods of time (during $8^{\text {th }}$ week at half semester and during $14^{\text {th }}$ week at the end of the semester). The first map was made after completion the first six lecture units (from 10 units that comprise the complete subject). Those maps were built after performing other activities that were taken in count for the final qualification of the subject (e.g. numerical exercises, reviews, information search activities and business cases). The week prior to the realization of the first map we introduced students to the technique in a 40-minute session to explain in detail what were the concept maps, what are the aim of using this technique, how was the building process and what aspects of the map were to be evaluated.

For building the first map we taught students a reduced and adapted version of Novak and Gowin (1996) recommended process, which consisted of 7 sequential steps:

1. Select the concepts from lectures,

2. Grouping concepts according a criteria of affinity,

3. Sort concepts from more abstract and general to more concrete and specific,

4. Write concepts within a geometric figure (a square or a circle),

5. Connect through a correct sentence to give meaning of the link between concepts

6. Check that the link provided is correct

7. Reflect the validity of the map constructed. 
Given the sample were students first course (second semester) and they previously only had attended one semester in college we decided to omit first step of the sequential and we choose and delivered concepts for students. So, we choose 15 basic concepts for the first map and 20 concepts for the last map. Some of the elected concepts were quite basic concepts that students already knew (e.g., employee or benefit) and they added some more specific they had learned during the first teaching of the subject units (e.g., benchmarking or transaction costs).

In regard to the evaluation of the maps we took into account several aspects:

- $\quad$ Direct relationships identified immediately

- $\quad$ Remote relationships identified

- $\quad$ Concepts that were not included but it could provide greater understanding of the subject

- $\quad$ The hierarchical structure of the map (order and grouping of concepts)

- $\quad$ The choice of 5 basic relationships that define the core of the subject.

Each group of students knew the importance of everyone of these aspects. In the same way we proceeded for the preparation of the second concept map, where 20 concepts were selected, of which some were new and others had been introduced to the student during the last units of the semester lectures.

After correcting maps we used qualifications to perform a correlation analysis with the aim of verifying whether the scores of the groups in the first map of the course are related to their grades in the final map of the course. We found that the mean scores on the two maps were positively and significantly correlated $(r=0.562, p$ $<0.05$ ). Subsequently we conducted a T-test analysis of mean differences (see Table 1) for related samples where we got that on the sample for the second map (the one we made at end of course) were significantly higher than those obtained in the first map. Therefore, we accept the working hypothesis where we supported the idea that due to the continuous and active learning process developed by working groups of students, they will have a better understanding and learning about the concepts of the subject, all which in turn results in obtaining a higher score on their qualifications (We founded an average increase in scores of 0.81 ).

Table 1. T-test and average qualifications for students

\begin{tabular}{|l|c|c|c|c|}
\hline & \multirow{2}{*}{$\begin{array}{c}\text { Average } \\
\text { qualification }\end{array}$} & \multirow{2}{*}{$\begin{array}{c}\text { Increase in } \\
\text { average } \\
\text { qualification }\end{array}$} & T-value & Significance \\
\cline { 1 - 1 } Sample for first map & 5.65 & 0.81 & -3.291 & \multirow{2}{*}{0.005} \\
\hline Sample for second map & 6.46 & & & T-test for related samples \\
\hline
\end{tabular}

\section{CONCLUSIONS}

In this paper we have tried to present a simplified view of theoretical foundations of what we call the process of building concept maps. Also we have shown a practical experience of concept mapping as a way to help students to enhance their active and meaningful learning. To emphasize the contribution of our work, we want to highlight the fact that this activity was developed as a complementary activity (assessed with $20 \%$ of the student's score) from other activities made during the semester. Therefore, we honestly think that the realization of this activity during the course has reinforced active learning process, and especially the interaction of students in the process of assimilation of new concepts.

Data of our empirical study shows how scores of students on average are higher at the end of the second map which reinforces our belief that the development of continuous activities throughout the semester will positively influence learning in students. However, despite the validity of the results achieved, it is necessary to indicate that this study has some limitations. One of the most important, and the more we focus on is that lacked a control group of students with which to strengthen the results achieved. Thus, a possible line of investigation for future work it could be developed collecting information on students during the first day of class as the final day and not only at the mid and end period of the semester. 


\section{AUTHOR INFORMATION}

Ricardo Martínez-Cañas, PhD in Business Management by University of Castilla-La Mancha. Assistant Professor of Management at Business Management Department. Faculty of Social Sciences of Cuenca, University of CastillaLa Mancha (Spain). E-mail: Ricardo.Martinez@uclm.es.

Research Interest: Social Capital, Teaching innovation, Meaningful learning

Pablo Ruíz-Palomino, PhD in Economics and Degree in Business Administration by University of Castilla-La Mancha... Assistant Professor in Management at Business Management Department. Faculty of Social Sciences of Cuenca. University of Castilla-La Mancha (Spain). E-mail: Pablo.Ruiz@uclm.es.

Research Interest: Business Ethics, Teaching innovation, Meaningful learning.

\section{REFERENCES}

1. Ausubel, D.P. (1968): Educational Psychology: A Cognitive View. Holt, Rinehart \& Winston, New York.

2. Ausubel, D.P. (2002): Adquisición y retención del conocimiento: Una perspectiva cognitiva. Barcelona, Paidós.

3. Castillo-Olivares, J.M. (2001): “Los mapas conceptuales en matemáticas”, Revista Números, 27, 45-58.

4. Gouli, E., Gogoulou, A., Paanikolaou, K. and Grigoriadou, M., (2004): "Compass: an adaptive web-based concept map assessment tool". Concept Maps: Theory, Methodology, Technology. Proceedings of the First International Conference on Concept Mapping, Pamplona, Spain.

5. Gouveia, V. and Valadares, J. (2004): “Concept maps and the didactic role of assessment”. Concept Maps: Theory, Methodology, Technology. Proceedings of the First International Conference on Concept Mapping, Pamplona, Spain.

6. Iuli, R.J. and Helldén, G. (2004): "Using concept maps as a research tool in science education research". Concept Maps: Theory, Methodology, Technology. Proceedings of the First International Conference on Concept Mapping, Pamplona, Spain

7. Moon, B.M., Hoffman, R.R., Novak, J.D., \& Cañas, A.J. (2011): Applied Concept Mapping: Capturing, Analyzing and Organizing Knowledge. CRC Press: New York.

8. Novak, J.D. (1998): Learning, Creating, and Using Knowledge: Concept Maps as Facilitative Tools in Schools and Corporations. New York, Routledge.

9. $\quad$ Novak, J.D. and Cañas, A.J. (2006): "The Theory Underlying Concept Maps and How To Construct and Use Them", Institute for Human and Machine Cognition. Accessed 24 Nov 2008.

10. Novak, J.D. and Gowin, D.B. (1996): Learning How to Learn, Cambridge University Press: New York. 
NOTES 